\title{
The Mechanisms of Collective Resilience in a Crisis Context: The Case of The 'COVID-19' Crisis
}

\author{
Bechir Mokline $^{1}$ (I) Mohamed Anis Ben Abdallah ${ }^{2}$
}

Received: 31 May 2021 / Accepted: 22 November 2021/Published online: 4 January 2022

(C) The Author(s) under exclusive licence to Global Institute of Flexible Systems Management 2021

\begin{abstract}
In this research, we claim to join the efforts of practitioners and researchers to provide managerial responses to an unprecedented health crisis such as COVID-19. To do this, we study the concept of 'collective resilience' as a mechanism for responding to crisis in the Tunisian context. The aim of this research is to explain the impact of collective resilience processes on the ability of organizations to withstand crisis. We conducted sixteen semi-structured interviews with Tunisian companies that had experienced the COVID-19 crisis. Continuous analysis of these interviews was carried out with the Nvivol2 software. Our results showed a positive effect of collective resilience on the capacity of organizations to resist the COVID-19 crisis by developing protective factors. These are manifested by new intersubjective interactions (massive exchanges, shared representation, collective consciousness, collaboration, solidarity, mutual aid, etc.), generic interactions (actions and assembly rules not used before: less formalized rules and procedures, more flexible and decentralized structure, new organizational diagrams based on trust, accountability, etc.) and finally the improvisation and tinkering of the organization which made it possible to bring about a change affecting all levels of the organization: strategic and organizational.
\end{abstract}

Bechir Mokline

bechir.mokline@gmail.com

Mohamed Anis Ben Abdallah

mohamedanisbenabdallah@yahoo.fr

1 Assistant professor at the Ibn Khaldoun University, 17, rue du 1er, Mai, 8020 Soliman, Tunisie

2 Assistant professor at the Faculty of Economics and Management of Nabeul, Campus Universitaire Mrezgua, 8000 Nabeul, Tunisie
Keywords Collective resilience · COVID-19 - Crisis . Organization $\cdot$ Pandemic $\cdot$ Weick

\section{Introduction}

Global economic, financial, sociological and health crises are raging in the twenty-first century (Abdallah et al. 2021; Polas \& Raju, 2021). The COVID-19 crisis is a good example of this premise. This is an unprecedented crisis in the sense that humanity has never experienced such a high level of economic and human impacts directly related to a virus (Frimousse \& Peretti, 2020; Gajdzik \& Wolniak, 2021). Face to this pandemic, companies need more than ever to develop not only protective factors that enable anticipation and resistance to crises, but also factors that enable them to operate resilience processes in sufficient numbers, be they individual or collective (Andersson et al., 2019; Blyth \& Mallett, 2020; Paul \& Chowdhury, 2020).

Generically, resilience can express the ability of a system to restore functions after shock or adaptability (Bryce et al., 2020; Duchek, 2020). From an organizational point of view, resilience is indeed the dynamic individual and collective ability to react properly to situations of adversity within the company. It matters for a company to anticipate the upcoming events and be able to adapt to those not yet conceived (Bustinza et al., 2019; Ishak \& Williams, 2018).

However, we find these resilience capabilities much more developed in the companies identified in the theoretical literature as HRO (High Reliability Organization). This type of organizations exists mainly in high-risk sectors such as the air companies, nuclear power plants and medical sector... Research that has studied these organizations in detail (particularly the work of Weick, 
(1987, 1988, 1993, 2003) began to analyze the concept of collective resilience in depth by studying its processes and key factors (Mendy, 2020; Roux-Dufort, 2003b).

The process of collective resilience is easily observed when a period of loss of collective sense is clearly identified because of the accumulation of incidents that paralyze the organization's activities over time. Thus, collective resilience is triggered by the emergence of intersubjective interactions (exchanges between individuals on acceptance, understanding the situation and actions to be decided and taken together) that take over generic organizational interactions (habits, procedures, hierarchical interactions,....). Collective action is then resumed after the chaos and fight against the crisis could be organized (Elcheroth \& Drury, 2020).

Based on the work of Weick (1987, 1988, 1993, 2003), we believe that observing organizational resilience in crisis time is tantamount to observing collective resilience processes and determining whether they affect negatively or positively the ability of the organization to cope with and emerge from the crisis either unscathed, diminished, or stronger.

Understanding the organization for Weick $(1987,1988,1993,2003)$ is understanding a dynamic process of collective action as described by certain interactionist theories from which he draws his considerations on social reality which is defined as a continuous process of communication, of interpretation and mutual adaptations (Koenig, 2003). It seems useful to us from this point of view to mobilize this Weickian thought to better understand the concept of resilience of the organization which consists in apprehending it as a dynamic process in particular of individual decisions and actions but also collective. This path, which we are following in the footsteps of Weick $(1987,1988,1993,2003)$ and interactionism, we know to be delicate because it is still weakly exploited by the scientific community as recalled by Koenig (2003, p.11): "In organizational sciences, the interactionist approach has yet to be exploited." However, we feel encouraged by the promising results that seem to emerge from this approach as they seem to us to be suitable for our research object: “From this point of view, Weick's work usefully complements existing theories on organizational reliability and crisis management" (Roux-Dufort, 2003a).

The objective of this research is to explain how the processes of collective resilience affect the organization's capacity to resist crises. We believe that the originality of this work lies in the insights provided on collective resilience as a defense mechanism in the face of a crisis in a Tunisian context. Indeed, despite Tunisia being one of the countries most affected by the health crisis, little research has been carried out on managerial responses to this health crisis (Mansour \& Ben Salem, 2020). Even the little work done so far on resilience to the Covid-19 crisis is still in an embryonic phase and the quality of their results is still poorly understood (Mokline \& Ben Abdallah, 2020). In the Tunisian context, we believe that we are the first to research the effect of collective resilience on the ability of companies to cope with the COVID-19 crisis. The results of this research could help companies (Tunisian and others) to improve their longevity during these difficult periods of increasing risks.

To carry out this work, we first introduce certain definitions of the concept of crisis in its various situations. Secondly, we provide a theoretical insight into collective resilience by revealing its processes and influence factors based on the work of Weick (1987, 1988, 1993, 2003), and other authors who join it. Next, we jointly address the three phases of collective resilience: the pre-crisis phase, the during-crisis phase and the post-crisis phase by noting their impact on crisis management within an organization. Finally, we explain our methodological approach as well as our empirical results from an analysis of thematic content of semi-structured interviews. These interviews were conducted at sixteen Tunisian companies that were affected by the COVID-19 crisis but managed to ensure their sustainability, at least in the first wave of the pandemic. We end with discussion of results and a conclusion that summarizes the final considerations of the research.

\section{Collective Resilience}

Most of the work on collective resilience was addressed by deploying the work on group resilience developed by Weick (1987, 1988, 1993, 2003); Altintas \& Royer (2009); Koninckx \& Teneau (2010); Rojot et al. (2006); RouxDufour (2003a); and Susara et al. (2020).

At the heart of Weick (1987, 1988, 1993, 2003), reflections on the reliability of organizations is the construction of sense making by individuals and the collective, vigilance and resilience. Organizational resilience means nothing more than to study it through individuals who make up the organization through their collective (Mokline \& Ben Abdallah, 2020).

Through his socio-cognitive approach to organization, Weick $(1987,1988,1993,2003)$ highlights the new interaction capabilities of individuals who, through the collective construction of sensing of situations, allow groups to overcome procedural rigidities to dynamically reconstruct others more suitable.

According to Roux-Dufort (2003a, p.27), In a crisis situation, these cognitive abilities ensure that individuals maintain together appropriate meaningful building processes to reconstruct a shared sense of the event and design their model of interaction in real time. 
The collective construction of sensemaking in crisis time takes place either in an intersubjective or a generic way. The intersubjective construction of sensemaking refers to the processes at work when two or more people communicate together and seek to synthesize and share their individual thoughts, intentions and feelings. Generic construction refers to the assembly of actions and rules emanating from routines and organizational procedures to transfer them from one member to another.

While these two registers of collective construction of sensemaking have differentiated characteristics (emerging, unique for intersubjective constructions, more stable, transferable and therefore more widely shared for generic constructions), they cannot be separated from the Weickian perspective (Allard-Poesi, 2003, p.13).

According to Weick (1987, 1988, 1993, 2003), the dynamic process of constructing sensemaking and interaction create organizational reality or makes it disappear, which he calls the ability to recover from a 'cosmological interruption' by the ability to avoid collapse of sensemaking. That is what he calls resilience.

For Weick (2003), resilience process is divided into three distinct generic major phases: the pre-crisis, during the crisis and the post-crisis period. Below, we deal in detail with each of these three phases. The purpose of this presentation is to identify the main protective factors or risk that promote or penalize the smooth running of collective resilience processes.

\section{Collective Resilience Process: The Pre-Crisis}

During this phase, protective or risk factors that may facilitate or penalize the resilience process are developed. It is also the period when the organization can develop its anticipatory, resistance or adaptation skills to potential future incidents (Elias, 2021).

According to Weick and Sutcliffe (2007), management of the unexpected is the quality to be developed in the beginning. In this sense, management must build capacity to accept individual and collective surprise and mistakes to enable the risk-taking necessary to face the threat of crisis (Polas \& Raju, 2021). It proposes that traditional organizations "copy" from highly reliable enterprises (HROs) the principles of organization and culture to foster resilience processes.

According to Flin (2008), the company will surrender to the growing threat of a crisis if it does not detect signals or fails to take appropriate reactions. According to Flin (2008), the business will give in to the growing threat of a crisis if it does not detect the signals or take the appropriate responses. Like Weick and Sutlcliffe (2007), he attaches importance to the cognitive skill of vigilance which should allow reflection on shock and crisis and thus avoid the blindness of managers.

Therefore, determining the warning signs of a crisis would be the first condition and one of the keys to resilience, but it is not so simple: For an individual, a crisis can only be seen as one push among other pressures. These differences in perception are even more difficult to understand because the members of an organization tend to minimize the warning signs of a crisis (Roux-Dufort, 2003a, p.36).

\section{Collective Resilience Process: During The Crisis}

During the crisis, 'sensemaking' is at the heart of resilience which, according to Weick $(1987,1988,1993,2003)$ is based on four principles: maintaining the role structure, respectful interaction, wisdom and tinkering.

\section{Role Structure}

A situation of crisis could cause a phenomenon of amplification where the members of the organization are jointly destroyed through their representation and structure by a gradual disappearance of sensemaking, especially those of the role structure. The usual modes of coordination (direct supervision, centralized hierarchy, etc.) no longer allow coherence of action and their gradual disappearance can lead to the destruction of structure. " ... The role system loses its structure leading to a loss of meaning, which leads to a new loss of structure and so on" (Weick, 2003, p.22).

So, the organization must pick up the weak signals that allow it to detect when to prioritize social interactions, put existing structures on the back burner and give way to the reconstruction of a new structural framework allowing again joint action to combat the crisis (Paul, 2020).

\section{Respectful Interaction}

In times of crisis, the organizational structure should disappear to give way for direct exchanges between members of the organization. If the role systems and the formal structure are to disappear, there is only one thing left to save the organization: respectful interaction. The latter is only possible if individual characteristics of trust, honesty and respect for oneself and the other are present (Weick, 2003). Indeed, these respectful interactions allow the improvisation of new solutions and actions that allow the re-operation processes, collective construction of sensemaking, representation and thus the restructuring of the organization: Interaction is only a first step. Trust, respect and honesty are also necessary ingredients to rebuild coherent bonds in situations where the role structure collapses. They allow mutual adaptation, unconditional 
imitation, role reversal and the ability to go from one leader to another, etc. The range of possibilities becomes wider and creativity becomes possible again (Roux-Dufort, 2003a, p.57).

Therefore, respectful interaction is a positive effect of resilience because it allows it to overcome the disintegration of organizational structure that is no longer able to coordinate collective action (Altintas \& Royer, 2009; Mendy, 2020).

\section{Tinkering}

Solutions in times of severe crisis are not part of the portfolio of responses acquired over time. You must have the reflex and the ability to invent new ones. This is the object of tinkering, i.e., improvisation and creativity (Roux-Dufort, 2003a).

At this stage, the Act of Resilience is not only a decision-making process but also a process of creating new solutions (Ahmed et al., 2021). According to Weick $(1987,1988,1993,2003)$, this is the characteristics of the handyman who should be creative and use what he knows to produce something he thought he could never achieve. Improvisation makes it possible to use the resources of the moment and gives individuals the opportunity to use previously unknown registers (Branicki et al., 2019; RouxDufort, 2003a).

\section{Wisdom}

Maintaining the role structure, fostering respectful interactions and do-it-yourself are three characteristics mentioned by Weick $(1987,1988,1993,2003)$ to foster organization's resilience. But the resilience process must be triggered before these three stated resilience factors develop. Then, the new events in question must be first identified in the company where blindness and avoidance are often more frequent. This is the object of the fourth characteristic that Weick $(1987,1988,1993,2003)$ refers to as wisdom and of which he makes a matter of attitude: "Wisdom is an attitude inverse to that of certainties, excessive trust and is closer to the attitude of doubt and questioning. Self-confidence of the 'wise' is limited." (Weick, 2003, p.33).

This is what allows the organization today not to think like yesterday even when it seems that nothing new has happened or is going to happen.

\section{Collective Resilience Process: Post-Crisis}

Several authors (Ferreira et al., 2020; Roux-Dufort, 2003b; Ursacki-Bryant et al., 2008) believe that crisis can be an essential source of organizational learning to prevent crises, reduce their impact or manage them more effectively. This may be an opportunity for changes to make the organization more resilient (Altintas \& Royer, 2009; Elias, 2021; Ishak \& Williams, 2018).

On the other hand, other work on post-crisis learning emphasizes the difficulty of learning from a crisis (Smith \& Elliott, 2007). According to this work, learning the organization is not in fact a decision-based choice. It is the result of a dynamic process linked to the possibilities of experimentation, error rights, requests for advice, officer assessment capabilities and executive skills (Altintas \& Royer, 2009; Linnenluecke, 2017; Pearson \& Mitroff, 1993).

But to learn resilience, would it be necessary to understand, observe and communicate it? We believe that resilience is not learned. It is a process whose success requires both internal faculties to the organization acquired over time and external faculties to find in the environment.

On the other hand, we are convinced that the protective skills to be developed by the company and minimization of risks can be learned after the crisis or by the study of other organizations that have acted on resilience (benchmarking).

\section{Research Methodology}

Our research aims to explore how collective resilience affects in a positive or negative way the resilience of organizations to a crisis, especially the health crisis of COVID-19. Following the example of Wacheux (1996), we consider that the qualitative approach fits the exploratory nature of the purpose of our research. According to Wacheux (1996, p.93) qualitative methodology is to follow or reconstruct events over time, assess local causalities and elaborate an explanation. It applies as much to an exploratory approach as to a desire to verify hypotheses.

The aim of our research is therefore exploratory, we do not therefore seek to generalize our research results, as in the context of quantitative studies, but rather to understand a subject little studied (such as COVID-19) in a context specific (such as Tunisia). The objective of our present study requires a qualitative approach particularly suited to exploration in order to build and structure a corpus of hypotheses on a very little studied field of research (Miles \& Huberman, 1991). Future research will aim to validate these hypotheses on other sites or by quantitative methods.

To collect data, we opted for the technique of semistructured interviews that promotes direct contact with individuals to obtain information. Semi-structured interviews allow the researcher more direct access to the individual's own perceptions. Interviews provide access to the conscious or unconscious mental world of individuals (Baumard et al., 2003). 
Table 1 Sample characteristics

\begin{tabular}{|c|c|c|c|c|c|}
\hline Case & Activity & Staff & Interviewees & & Duration of interview \\
\hline $\mathrm{C} 1$ & Food & 920 & Chairman and CEO & I1 & $55 \min$ \\
\hline $\mathrm{C} 2$ & Agricultural & 880 & Manager & $\mathrm{I} 2$ & $50 \mathrm{~min}$ \\
\hline $\mathrm{C} 3$ & Chemical industries & 820 & Managing Director & $\mathrm{I} 3$ & $48 \mathrm{~min}$ \\
\hline $\mathrm{C} 4$ & Mechanical industries & 760 & Deputy Managing Director & $\mathrm{I} 4$ & $47 \mathrm{~min}$ \\
\hline $\mathrm{C} 5$ & Pharmaceuticals & 680 & Deputy Managing Director & I5 & $45 \mathrm{~min}$ \\
\hline C6 & Metallurgical industries & 630 & Human resources manager & I6 & $60 \mathrm{~min}$ \\
\hline $\mathrm{C} 7$ & Electrical industries & 602 & CSR Manager & $\mathrm{I} 7$ & $53 \mathrm{~min}$ \\
\hline $\mathrm{C} 8$ & Metallic industries & 590 & Manager of Sustainable Development & I8 & $46 \min$ \\
\hline C9 & Cosmetics & 550 & Manager of quality, safety and environment & I9 & $42 \mathrm{~min}$ \\
\hline $\mathrm{C} 10$ & Building Materials Industries & 510 & Manager of Research and Development & $\mathrm{I} 10$ & $56 \mathrm{~min}$ \\
\hline $\mathrm{C} 11$ & Ceramics and Glass Industries & 500 & Production manager & $\mathrm{I} 11$ & $35 \mathrm{~min}$ \\
\hline $\mathrm{C} 12$ & Recycling and the environment & 487 & Health and safety manager & $\mathrm{I} 12$ & $40 \min$ \\
\hline $\mathrm{C} 13$ & Tourism & 440 & Communications manager & $\mathrm{I} 13$ & $48 \mathrm{~min}$ \\
\hline $\mathrm{C} 14$ & Real estate promotion & 399 & Social assistant & $\mathrm{I} 14$ & $42 \mathrm{~min}$ \\
\hline $\mathrm{C} 15$ & Paramedic & 355 & Quality technician & $\mathrm{I} 15$ & $50 \mathrm{~min}$ \\
\hline $\mathrm{C} 16$ & Textile & 290 & Worker & $\mathrm{I} 16$ & $51 \mathrm{~min}$ \\
\hline
\end{tabular}

We favored an approach of the "thematic content analysis" type as a method of processing the data collected. This step (content analysis) consists in transcribing the qualitative data, coding, processing and evaluating them in order to have final research conclusions (Andreani \& Conchon, 2005). Therefore, we carried out coding work in several stages.

First, we transcribed the interviews using a Microsoft Word processor, arranging the information collected in the form of texts (verbatim). Then, we performed the data coding to develop a thematic grid. Then, we performed the data coding to develop a thematic grid. The coding was carried out using the 'Nvivo 12' software. This software allowed us to break down the content of the interviewees' speech into units of analysis (words, sentences, themes, etc.) and integrate them into categories defined according to the objective of the research (Deschenaux, 2007). Finally, we identified interpretations and asked our interviewees to have their assessment of our results. After their validation, we put forward our final results.

We conducted sixteen interviews over a period of more than seven months from April 2020 to November 2020 with an average duration of $50 \mathrm{~min}$. We chose to interview people at all levels of management (leaders, managers and non-executive employees) to gain access to a diversity of views (Demers, 2003) and to avoid elite bias (Miles \& Huberman, 1991).

We chose to conduct these interviews in sixteen Tunisian companies that faced difficulties (financial economic and organizational) because of the harmful effects of the
COVID-19 crisis but that were able to resist and ensure sustainability in the first wave of the pandemic. These companies are large and medium-sized and in distinct industries. We believe that the number of our sample meets the principle of theoretical case saturation advocated by Yin (2003).

Table 1 summarizes the characteristics of our sample.

\section{Results}

It is undeniable that the COVID-19 crisis was an unprecedented shock to the whole world and wreaked havoc on an individual, private, and professional level in different countries. In Tunisia, managers and employees have been forced out of their comfort zone and they broke with their usual reflexes, routine roles and respective positions. The changes have affected organizational structures as well as work patterns, interpersonal relationships and workers' expectations.

"The COVID-19 crisis has caused a real upheaval in our company. It has affected us in all respects: financial, structural, organizational... It has forced us to make radical changes in our traditional managerial practices. This made us reinvent a social contract capable of ensuring the collective mobilization of all members of the organization and creating a staff endowed with dynamic capacity for resilience" (I1). 
In our empirical study, we seek to explore the three phases of collective resilience processes (before, during and after the crisis) in a real-world organizational context. We analyze these three phases in detail in the following sections.

\section{Phase of Collective Resilience Before Crisis}

This phase begins with the advent of a disruptive event for the company that is the health crisis of COVID-19. The beginning of such crisis is an individual perception that can be received simultaneously in the same way or differently by many individuals. There are three different perceptions observed in our empirical study: blindness to the event, recognition of the event and avoidance behavior. They will be illustrated in the following part.

\section{Blindness at the Event}

The crisis caused by the COVID-19 pandemic has spread exponentially causing havoc on all levels: social, financial, economic....However, at the level of most of the companies studied, the staff initially experienced a sense of blindness to the crisis in the sense that they did not realize its repercussions. Indeed, the warning signs of the crisis are not seen due to lack of culture of anticipation and adaptation with change, lack of vigilance and/or insufficient preparation of individuals and groups.

"At first, our working staff was unable to decipher all the information. It was not able to detect the early weak signals of the crisis. Indeed, the workforce were not necessarily ready to adapt to the change caused by a generalized crisis. They are not used to recognizing a state of crisis, either because they have not experienced such crises within their company before, or they have experienced a crisis but not as serious as that of COVID-19" (I13).

\section{Recognition of the Event: Accumulation of Disruptive Events}

The proliferation of COVID-19 crisis's repercussions was staggering. The pace of the national and international economy has been halted by very strict security measures: the closure of international borders, general containment and curfew in most countries of the world. The COVID-19 pandemic has exposed Tunisian companies to greater supply, export and marketing difficulties that resulted in production chain disruptions, and consequently strategic sustainability and sustainability problems.
"While it is not over yet, the COVID-19 crisis has already showed us how our reflections and practices are not always in tune with reality. We thought our company was invincible to change. Now, we recognize we were wrong and that a crisis has hit us. This crisis has revealed our lack of control and preparedness to the unpredictability of hazards that could threaten our existence on a large scale and in the short term" (I3).

\section{Avoidance Behavior Following the Crisis}

The world of work is paralyzed by the emergence of the COVID-19 crisis. Everyone, regardless of his position in the organizational hierarchy, finds it upended in his personal, professional and social life. Therefore, individuals are faced with a traumatic condition that has generated psychosocial risks manifested in feelings of anxiety, uncertainty, tension, stress and depression. However, the interviewees denied these difficult situations. They experienced defensive and protectionist reactions to neutralize internal tensions and resume emotional balance, which triggered an attitude of avoidance by embodying the idea that the difficult situation is only an ephemeral event that will fade after some time. Management will strive to take curative actions to absorb the effects of the crisis.

\begin{abstract}
"The situation arising from the crisis is traumatic causing some feelings of anxiety and stress of worthlessness. The situation is getting worse and the future is unclear. Some have chosen to strip down the reality to calm down psychologically thinking that the solution will be found quickly and that the management of the company will react and face the crisis to return to normal situation" (I6).
\end{abstract}

\section{During the Crisis}

In this phase, the goal is to deal with the crisis. Resilience takes the form of responsiveness following a loss of sensemaking, and collective resistance by creating new practices that were of little or not used in the company before. This phase consists of five consecutive steps: loss of sensemaking, reconstruction of sensemaking, creation of intersubjective interactions, reconstruction of generic interactions and development of the organization.

\section{Loss of Sensemaking: Cosmological Episode}

This feeling came after the staff understood the situation and the consequences of the crisis. The cosmological episode has spread to the whole company that has not understood what happened. The consequences of the 
pandemic have led to many changes in behavior that management and employees probably had not anticipated such as work duration, the telework imposed by the confinement, the taking of leave (all reasons included), the particular modes of pay and working conditions (partial unemployment, loss of part of salary), the management of allowances/ allowances paid to employees (following dismissal)...

And then, in parallel, a management appeared which locked itself in deafening silence. It has failed to ensure the safety of employees in a credible way. It resorted to technical unemployment, allowing the state to nationalize the payment of wages and to guarantee the loans of the company.

This situation created a state of shock that resulted in a period when the staff was unable to act. They can't believe what is happening.

"It's a shock and it's hard to deal with it right away.

It's a disaster. We could not assess the impact at that time. We were completely unplugged. We had never thought that such a situation could happen by going beyond our preventions that had been studied, analyzed and verified. Paralysis was the key word of the situation and we lost the sense of action" (I2).

\section{Reconstruction of Sensemaking of Action}

The reconstruction phase was accompanied by feelings of insecurity and anxiety after a sharp stage of loss of sensemaking. This is the time when there are more questions than answers and when individuals have mixed feelings of hope and mistrust. During this period, the staff begins to search for new meanings that help them react satisfactorily to emerging situations. They are in the process of appropriating new sensemaking that allows them to reconstruct their perception of the world.

One of the first reactions observed in our empirical study to carry out this reconstruction was to activate tactics to simplify events; this therefore corresponds to a form of cognitive normalization. The objective was to reduce complexity and uncertainty to provide a chance for action and decision. By this logic, the staff sought to place the event of the crisis in acceptable frameworks and frames of reference in order to get rid of emotional consequences and prepare for anti-crisis action.

"Once the shock of the brutality of the cessation of activities passed, everyone imagined: how to accept the reality of the crisis? The aim was to make the crisis socially and psychologically acceptable in order to resume the normative register that the crisis eroded" (I11).

\section{Creating Intersubjective (Interpersonal) Interactions}

Faced with a problem as complex as the pandemic, no one can solve it alone, which requires the contribution of all. Collaboration then imposed itself within an organization and required recognized and accepted interdependencies between the different actors involved.

We thus qualify this type of interdependence as "intersubjective interactions" (personal and professional exchanges between individuals, understanding the situation and the actions to be decided and taken together). Especially in the context of a health crisis, this condition is itself based on solidarity and mutual aid.

"To face an unprecedented crisis, solidarity and mutual aid are the levers that allow us to overcome very difficult situations for the well-being of all stakeholders of the organization. This strength of partnership and mutual aid are what make us even more human. Only together-managers and employees-we can overcome all difficulties" (I7).

In crisis management, policy makers have relied on the search for the collective spirit and intelligence of staff to bring out the public interest, sometimes even at the expense of individual interests. Thus, silo work has given way to collaborative work that has facilitated joint reactivity, and thus collective resilience.

"We were able to absorb the phenomenon of 'silo' which explains the natural tendency to think and govern on its own because one's self is more truthful and important than the others. This was necessary because work in times of crisis is a form of collective mobilization. The latter nurtures the ability to improvise and collective and organizational resilience" (I5).

Then, collaboration has enabled a collective awareness of the reality of the crisis and a shared co-construction of how to cope with adversity.

"We wanted to stick together in the face of adversity far beyond the health crisis. Our desire to work together is based on the need to save lives. As a result, we have appealed to a strong reason that creates meaning in order to transcend our natural behaviors of competition and individualism and establishes a collective consciousness of resistance to the crisis" (I10).

Following the announcement of general national confinement by the government decree of 20/03/2020, many companies have been pushed to deploy teleworking as a remote working mode and of which a large number of employees have little or no do the experience. However, 
this mode of remote work has surprisingly brought teams closer. It has enabled employees to develop new skills and habits of work, collaboration and learning.

\begin{abstract}
"The containment experience has allowed us to have new ways of communicating and interacting in online mode. We have learned to collaborate through e-proximity to ensure sustainable operations of the company. All this has generated an outpouring of cooperation, solidarity, mutual aid, trust and various events to foster this sense of belonging to a community" (I16).
\end{abstract}

\section{Reconstruction of Generic (Organizational) Interactions}

The COVID-19 health crisis has pushed organizations to adopt other forms of work organization and management. We moved on to remote management, telecommuting, partial unemployment but above all the use of digital tools to limit human contact. The company was obliged to break with the traditional and conventional model of team animation. We call this organizational dynamic by 'generic interactions' (organizational habits and procedures, hierarchical interactions...).

However, the importance of maintaining social link and the impossibility of close management have led to the development of accountability. This finding highlights a different relational model than that inherited from neoTaylorism. Based on trust and autonomy, this model is not only possible, but also a source of fulfillment and efficiency. During the crisis, the organization became more flexible for employees mobilized at their workplace. Working remotely has led the organization to revisit work toward a better reconciliation of work and personal life. Vertical hierarchical organizational structures have been replaced by transverse and decentralized horizontal structures. These transformations can only be built on trust, exchange, sharing and new forms of interpersonal solidarity between employees themselves and toward their managers.

"The current health crisis has led to a radical rethinking of professional activities, representations, routines and undermined certainties in organizational practices. Our company has made structures more decentralized, flexible and cross-cutting to ensure initiative, autonomy and accountability. The result of this change was a collective mobilization allowing the federation of all efforts to resist the crisis. "(I8).

Distance required innovation in communication, forms of evaluation and delegation. The strengthened autonomy of the employees has resulted in a co-construction of new operating standards in the team. As a new key skill, telemanagement has forced managers to improve their practice to replace institutional distrust with a sense of trust.

"This health crisis has been a trigger for our company's awareness of the benefits of working remotely, the autonomy of workers and the flexible organization of their working time along with reconciliation of their private and professional lives. Revisiting processes, questioning the choices of employees' support, imagining new solutions to establish digital leadership and empowerment of employees by favoring collaborative social networks and imposing a new type of social dialogue without switching to the dismissal of workers are modalities of action imposed to prepare for a better future" (I4).

\section{Organizational Development}

At this stage, the collective's actions of resilience should contribute either to the failure or the success of the organization resilience. In our empirical study, the companies studied were able to ensure their sustainability and development by exploiting collective resilience in a positive way. They marked an organizational change resulting from the joint effort of all parties involved in the organization.

"Living in a crisis brings a very important leap in maturity on a human level. The important thing in this crisis is the solidarity of the employees of the company, which has confirmed the effectiveness of the organization in crisis management. Today, the most profitable investment that is available in our collective consciousness is to have to change" (I15).

This organizational change led to new management practices that had been of little or no use in these companies previously, and that have affected several levels of the organization: strategies, work, technology, management, human resources management, business policies and corporate social responsibility.

In this sense, the crisis offered an opportunity to review the mechanisms of crisis management such as the safeguard plan, business continuity plan, recovery plan, Risk Management, etc. Henceforth, companies will acquire these crisis management tools to invigorate their detection and response capabilities and to anticipate potential risks by making strategic choices based on digitalization and ICT.

Sustainability of operations in periods of containment was also one of the strategic and operational thinking that ensured the survival and sustainability of companies in the most difficult episodes of adversity. This is addressed by 
several measures such as the use of financial reserves, optimization of costs through Lean Management approach and adoption of new business practices that were not previously used: online sales, contact with the customer via telework, partnership with transport companies for delivery and home delivery.

"The COVID-19 crisis has redefined strategic and
operational choices of the company. The challenge
was to give up the traditional strategic models and
opt for others better able to ensure the continuity of
the company in a context of crisis and risk. At this
level, the adoption of crisis management tools such as
the safeguard plan, continuity plan, health policy,
risk management, reorganization of trade policy...
was the best choice to ensure the sustainability of our
business" (I9).

The health crisis was also an opportunity to review the internal communication policy of companies. In fact, in the midst of the spread of the Coronavirus, rumors and also false information are intensifying in companies, in particular with regard to the bad economic and social repercussions of the epidemic, and organizational responses to it. Unfortunately, the massive dissemination of these types of information is harmful and creates anxiety because of its fear-mongering approach.

Supported by bad interpretations, they reinforce the mechanisms of psychosis and disrupt the personal and professional lives of employees. Aware of this problem of disinformation, companies have taken care to communicate regularly and transparently on the evolution of the crisis situation by collecting information only from official State establishments and this in order to avoid any misinterpretation, false rumor and excessive fear...

This could reassure employees and allow companies to react in time on the basis of reliable information. These results are consistent with the study by Tam et al. (2021) which showed the importance of the Vietnamese government's communication policy in the emotional management of Vietnamese. Indeed, by having adequate information / knowledge about the COVID-19 pandemic, the majority of Vietnamese experience low levels of emotional anxiety, dread, fear, stress and panic. In addition, the communication strategy has contributed to fostering health promotion and safety development behaviors within the community (Tam et al., 2021).

"False information and rumors that arise in times of crisis reinforce the mechanisms of psychosis concerning the future and the safety of employees. To this is added an anxiety-inducing phenomenon which is infobesity which only feeds our uncertainties and our fears in the face of the unknown and it has developed forms of obsessive anxiety as well as irrational behaviors (phobia of cleanliness, folds, white virus...). But this meteoric epidemic of information has made us aware of the impact that information could have on our moral and psychological health. That is why we have adopted a transparent communication policy by cooperating with official public establishments in order to convey all the facts to the employees" (I9).

However, we draw attention to the fact that the success of companies in ensuring their sustainability has not been achieved without collateral damage. Rather, it was carried out to the detriment of the destruction of certain assets of all shareholders (decrease in capital, closure of certain subsidiaries, dismissal of part of the workforce, loss of some social benefits, hierarchical degradation, partial unemployment and reduction in wages).

"Every success comes at a price, it's a human certainty. The success of our company in terminating and ensuring its continuity was associated with a set of losses that affected everyone regardless of their hierarchical position. Deficit, death of a loved one and degradation.., are all signs of damage caused by this crisis. In short, we have no choice as we were forced to adapt with our new situation psychologically and grieve to bounce back" (I14).

\section{Phase of Collective Resilience After Crisis}

The COVID-19 pandemic has led the workforce to trigger a process of collective resilience to face the crisis and ensure the sustainability of the company. It represents a rich teaching experience for the company and employees. Feedback is a collective exercise that takes place in a participatory manner with the company's stakeholders (managers, employees and shareholders). Experience feedback makes it possible, on the one hand, to assess the new practices put in place in the organization to circumvent the fallout from the crisis, and on the other hand to prepare for next crises, since companies are now faced with a succession of crises of all kinds, constantly intersecting and interfering (Elias, 2021).

Our discussions reveal the following lessons that companies must learn from this crisis:

- Companies have to make the crisis management activity more professional by creating an entity "Continuity Plan" responsible for anticipating crises and managing them within their professional Units. Everyone must therefore be made aware of risk detection because the more attentive employees are, the more risks, even the most imperceptible, are likely to be treated. Crisis exercises 
can be an effective way to raise awareness of crisis characteristics and the culture of resilience face to adversity in the company.

- Business organizational and operating models need to be considered differently to ensure economic performance. Digitalization, telecommuting, goal management and flexibility help to adapt to unpredictable developments.

Managers have to ensure better listening for their employees who have contributed in the difficult phase to ensure the sustainability of their company. They are also required to develop policies that give more space to the human factor and its development (well-being, occupational medicine, personal development, etc.).

- There is an urgent need to think about a new balance between working remotely and working in the company. This requires rethinking the organization of work in a flexible way with management methods adapted to the exercise of activities on site or remotely. Workspaces also have to evolve both within the company to promote cooperative and relational working practices and at home for an optimum workspace.

"The crisis has been an endurance test of our organizations. However, lessons must be learned to anticipate further disruptions and/or other crises. Of course, we do not wish to experience such a crisis again, but feedback offers us both a closed diagnosis of our companies while allowing us to work for a turbulent and non-linear future as well as preparation for crisis management and HR" (I12).

\section{Discussion of Results}

Based on the work of Weick $(1987,1988,1993,2003)$ and some authors who join him in his approach, we were first able to introduce the three phases of collective resilience in our theoretical part: the pre-crisis, during the crisis and the post-crisis period. Then, we attempted to recognize these three phases in our empirical study.

In the pre-crisis phase, we showed that the COVID-19 crisis has been sudden and profound for many companies and employees. However, the group experienced a blind reaction in the beginning, then an avoidance reaction following the recognition of disruptive events of the crisis. There are two reasons for this reaction: either the company did not experience a crisis before, or it has experienced it but not with the magnitude of that of COVID-19. Such lack of experience has confused the collective's ability to discern the first signs of the crisis. These results are at odds with the assertion by Weick and Sutlcliffe (2007) that the members of the organization should be able to have a sense of vigilance and anticipation (through the management of the unexpected and the cognitive competence of vigilance), which is necessary to avoid the amplification effect that could cause inappropriate actions and consequently a retrospective loss of collective sensemaking (Roux-Dufort, 2003a).

The crisis phase is a key phase as it introduces the most concrete actions of collective resilience. In this phase, we observed a great compatibility between our empirical results and the literature. Indeed, the latter begins with a loss of sensemaking that manifests itself in a state of shock preventing the collective from understanding what is happening and acting. Subsequently, a reaction of reconstruction of sensemaking manifests itself in the collective by creating a new cognitive map and a new representation of the world announcing the first actions of reactivity to the crisis (sensemaking in the sense of Weick, (1987, 1988, 1993, 2003). These reactions begin with new intersubjective interactions (massive exchanges, shared representation, collective consciousness, collaboration, solidarity, mutual aid...) and also generic interactions (use of directories of actions and assembly rules not used before: less formalized rules and procedures, more flexible and decentralized structure, new organizational schemes based on trust, accountability... (intersubjective and generic construction in the sense of Weick, 2003 and RouxDufort, 2003a).

We showed that during these intersubjective and generic interactions, the collective has succeeded in developing respectful interactions (Branicki et al., 2019; Weick, 1993) based on collaboration, solidarity, sharing, mutual aid, collective awareness, co-construction of solutions and remote socialization. This same collective showed wisdom (Weick, 1988; Altintas and Royer, 2009) when they were able to surpass the phenomenon of 'Silo' which reflects narcissistic and individualistic tendencies. Some managers have been able to reorganize the role structure system (Mendy, 2020; Weick, 1987) by continuing to animate their team remotely with more accountability and individualized support. These required new modes of more flexible and decentralized structures that favored the autonomy and initiative of shareholders. The development of the organization that marked the success of resilience processes and the continuity of the company was an opportunity to confirm the improvisation and tinkering of the organization (Roux-Dufort, 2003a; Weick, 2003).

However, we noted some differences with the literature in this phase. In this sense, we note that there are other factors that we found in our empirical study but are not listed in the work of Weick, $(1987,1988,1993,2003)$ and some authors who join him in his approach (such as: Altintas \& Royer, 2009; Branicki et al., 2019; Mendy, 2020; Roux-Dufort, 2003a). These include cognitive normalization and bereavement. As for standardization, it presents 
itself as a simplification technique to reduce complexity, anxiety and uncertainty in order to achieve latitude in decision-making and action. Grief manifests itself in psychological adaptation to damage to all members of the organization.

The post-crisis phase was an opportunity to provide feedback that aims to assess the changes adopted during the crisis and to draw organizational learning that can prevent and deal with future crises (Ferreira et al., 2020; RouxDufort, 2003b; Ursacki-Bryant et al., 2008) and therefore this could allow the company to be more resilient (Altintas \& Royer, 2009; Ishak et Williams, 2018). In appearance, the theoretical phase and the empirical phase of the postcrisis coincide. However, the crisis has not passed yet and we believe that it is early to assess the continuity of changes and the effectiveness of learning in companies.

\section{Conclusion}

The COVID-19 effect was rapid and significant for organizations. Management is no longer just distributing tasks, allocating budgets and coordinating the work of employees. It is also adapting the organization to uncertainty and unexpectedness. Now, all companies must manage increasingly frequent crisis situations. Therefore, it is important for them to know and develop protective factors to better face the crisis. Collective resilience is one of those factors that could potentially enable companies to withstand crises.

We have attempted in this research to reveal how the processes of collective resilience influence the capacity of the organization to resist or not to the crisis.

To do this, we succeeded in studying the process of collective resilience through its three phases (before the crisis, during the crisis and after the crisis) in sixteen medium- and large-sized Tunisian companies that have been subject to the negative effects of the crisis but were able to guarantee their survival in the first wave of the pandemic. These observations were made possible by sixteen semi-structured interviews with leaders/managers/workers who experienced this crisis.

The originality of our research lies in its innovative and particular aspect. Indeed, despite the importance of the results of previous studies on the management of the COVID-19 crisis, to our knowledge no research has been interested in collective resilience as a mechanism for responding to the COVID-19 crisis, particularly in the Tunisian context.

The results of our research make it possible to identify a significant contribution of collective resilience to the resilience of Tunisian companies (especially medium and large) in the face of the COVID-19 crisis. Indeed, collective resilience allows these companies to have protective factors which are envisaged through new intersubjective interactions (massive exchanges, shared representation, collective consciousness, collaboration, solidarity, mutual aid, etc.); generic interactions (use of repertoires of actions and assembly rules not used before: less formalized rules and procedures, more flexible and decentralized structure, new organizational schemes based on trust, accountability, etc.); role structures by adopting remote management with more accountability, confidence, autonomy and individualized support; and finally the improvisation and tinkering of the organization which announces a change affecting all levels of the organization: strategic and organizational based on collective creativity (initiative, ingenuity and resourcefulness), cognitive normalization (reduction of complexity, anxiety and uncertainty to free up decision and action latitude) and mourning (psychological adaptation in the face of damage affecting all actors in the organization).

In this trend, we can make some initial managerial suggestions in human resources management, governance and crisis management. These suggestions enable companies to develop protective factors that promote collective resilience processes, hence the effectiveness of responsiveness and rebound in times of crisis.

Our suggestions are based on:

- The recruitment of staff with significant experience in highly reliable organizations (HRO). Their recruitment will eventually contribute to increasing the protective factors within the company because they had certainly developed important qualities and quasi reflexes of vigilance and anticipation in times of crisis.

- The training of existing collective on the bases of Risk Management to raise their vigilance and improvisation's capacity.

In the end, it should be noted that the results presented in our research should not be considered beyond their exploratory nature. On the one hand, these results are imbued with certain subjectivity since the interviewees had their own interpretation of the events. On the other hand, the researcher was also subject to the influence of his own interpretations of the narrative in his coding. Second, our results did not identify correlation between collective resilience and organizational resilience.

Therefore, we recommend that future work mitigates the subjectivity of this work by opting for a larger and more varied sample on the same case that will be analyzed with longitudinal analysis methods over longer periods of time. On the other hand, it would be appropriate to use a larger number of cases and do coding recommend of the same case by several researchers. 
At this level, we recommend that future researchers base themselves on two important references when conducting future research on the concept of resilience in a context of crisis namely Tam et al. (2021) and Ufua et al. (2021). We believe that the results of these two studies are of great value, since they dealt very rigorously with the management of the Covid-19 crisis by presenting remarkable contributions on this subject.

Finally, it is important to check the real impact of collective resilience on the effectiveness of organizational resilience in the context of the COVID-19 crisis.

Funding There is no funding for this article.

\section{Declarations}

Conflict of interest The authors declare that they have no known competing financial interests or personal relationships that could have appeared to influence the work reported in this paper.

\section{References}

Abdalla, M., Alarabi, L., \& Hendawi, A. (2021). Crisis Management Art from the Risks to the Control: A Review of Methods and Directions. Information, 12(1), 18-48.

Ahmed, S., Taqi, H. M. M., Farabi, Y. I., Sarker, M., Ali, S. M., \& Sankaranarayanan, B. (2021). Evaluation of flexible strategies to manage the COVID-19 pandemic in the education sector. Global Journal of Flexible Systems Management, 22(Suppl 2), S81S105.

Allard-Poesi, \& F. (2003). Collective sense and collective construction of meaning, in: The meaning of action: Karl Weick: sociopsychology of the organization, Paris: Vidaillet B., Vuibert.

Altintas, G., \& Royer, I. (2009). Strengthening resilience through post-crisis learning: A longitudinal study of two periods of turbulence.M@n@gement,12(4),266-293.

Andersson, T., C-ke, M., Tengblad, S., \& Wickelgren, M. (2019). Building features for organizational resilience through balancing organizational structures. Scandinavian Journal of Management, 35(1), 36-45.

Andreani, J. C., \& Conchon, F. (2005). Reliability and validity of qualitative surveys: A state of the art in marketing. French Marketing Review, 201, 5-21.

Baumard, P., Donada, C., Ibert, J., \& Xuerb, J. M. (2003). Data collection and the management of their sources. In R. A. Thiétart (Ed.), Management research methods (pp. 224-256). Dunod.

Blyth, M., \& Mallett, S. (2020). Epidemics and pandemics: Effects on societal and organizational resilience. Journal of Business Continuity Emergency Planning, 14(1), 17-36.

Branicki, L., Steyer, V., \& Sullivan-Taylor, B. (2019). Why resilience managers aren't resilient, and what human resource management can do about it. The International Journal of Human Resource Management, 30(8), 1261-1286.

Bryce, C., Ring, P., Ashby, S., \& Wardman, J. K. (2020). Resilience in the face of uncertainty: Early lessons from the COVID-19 pandemic. Journal of Risk Research, 23(7), 880-887.

Bustinza, O. F., Vendrell-Herrero, F., Perez-Arostegui, M. N., \& Parry, G. (2019). Technological capabilities, resilience capabilities and organizational effectiveness. The International Journal of Human Resource Management, 30(8), 1370-1392.
Demers, C. (2003). The interview. In Y. Giordano (Ed.), (coord) Lead a research project: a qualitative perspective (pp. 173-210). Paris: Management and Company Editions (EMS).

Deschenaux, F. (2007). Introductory guide to QSR Nvivo 7 software The educational booklets of the association for qualitative research. Quebec: National Library of Quebec.

Duchek, S. (2020). Organizational resilience: A capability-based conceptualization. Business Research, 13(1), 215-246. https:// doi.org/10.1007/s40685-019-0085-7

Elcheroth, G., \& Drury, J. (2020). Collective resilience in times of crisis: Lessons from the literature for socially effective responses to the pandemic. The British Psychological Society, 59(3), 703-713.

Elias, A. A. (2021). Kerala's innovations and flexibility for Covid-19 recovery: Storytelling using systems thinking. Global Journal of Flexible Systems Management, 22(1), 33-43. https://doi.org/10. 1007/s40171-021-00268-8

Ferreira, R. J., Buttell, F., \& Cannon, C. (2020). COVID-19: Immediate predictors of individual resilience. Sustainability, 12(1), 64-95.

Flin, R. (2008). Erosion OF Managerial Resilience: From Vasa to Nasa, in: Resilience Engineering. Aldershot, United Kingdom: Concepts and Precepts, 223-234.

Frimousse, S., \& Peretti, J. M. (2020). The lasting impact of the crisis on management. Management Questions, 2(28), 159-243.

Gajdzik, B., \& Wolniak, R. (2021). Influence of the COVID-19 crisis on steel production in poland compared to the financial crisis of 2009 and to boom periods in the market. Resources, 10, 4.

Ishak, A. W., \& Williams, E. A. (2018). A dynamic model of organizational resilience: Adaptive and anchored approaches. Corporate Communications: An International Journal, 23(2), 180-196.

Koenig, G. (2003), L'organisation dans une perspective interactionniste, in B. Vidaillet (dir.), Le sens de l'action, Paris: Vuibert, pp. $15-34$

Koninckx, G., \& Teneau, G. (2010). Resilience a new concept, In: Organizational Resilience. Bouncing back in the face of turbulence, Boeck, Paris

Linnenluecke, M. K. (2017). Resilience in business and management research: A review of influential publications and a research agenda. International Journal of Management Reviews, 19(1), 4-30.

Mansour, N., \& Ben Salem, S. (2020). Socio-economic impacts of covid-19 on the Tunisian economy. Journal of the International Academy for Case Studies, 26(4), 1-13.

Mendy, J. (2020). Bouncing back from Workplace Stress: From HRD's Individual Employee's Developmental Focus to Multifacetted Collective Workforce Resilience Intervention. Advances in Developing Human Resources, 22(4), 353-369.

Miles, M.B., \& Huberman, A.M. (1991). Analysis of qualitative data: A collection of new methods. Brussels: De Boeck. Translation of Analysing qualitative data: A source book for new methods, 1979, 1984. Bruxelles: De Boeck.

Mokline, B., \& Ben Abdallah, M. A. (2021). Individual Resilience in the Organization in the Face of Crisis: Study of the Concept in the Context of COVID-19. Global Journal of Flexible Systems Management., 22(1), 219-231. https://doi.org/10.1007/s40171021-00273-X

Paul, S. K., \& Chowdhury, P. (2020). Strategies for managing the impacts of disruptions during COVID-19: An example of toilet paper. Global Journal of Flexible Systems Management, 21(3), 283-293. https://doi.org/10.1007/s40171-020-00248-4

Pearson, C. M., \& Mitroff, I. I. (1993). From crisis prone to crisis prepared: A framework for crisis management. Academy of Management Executive, 7(1), 48-59. 
Polas, M. R. H., \& Raju, V. (2021). Technology and entrepreneurial marketing decisions during COVID-19. Global Journal of Flexible Systems Management, 22(1), 95-112. https://doi.org/ 10.1007/s40171-021-00262-0

Rojot, J., Wacheux, F., \& Weick, K. E. (2006). Subtle Theorist of Complexity: Space, Time and Interactions. In A. David \& F. Bensebaa (Eds.), The Challenges of Corporate Sensemaking Karl E. Weick and Management Sciences (pp. 127-133). Paris: Economica.

Roux-Dufort C. (2003a). The construction of a theory of organizational reliability, In: The meaning of the action: Karl Weick: sociopsychology of the organization, Paris: Vidaillet B., Vuibert.

Roux-Dufort, C. (2003b). Manage and decide in a crisis. Dunod.

Smith, D., \& Elliott, D. (2007). Exploring the barriers to learning from crisis. Management Learning, 38(5), 519-538.

Susara, E., Biggs, R., \& Preiser, R. (2020). Sensemaking as an approach for resilience assessment in an Essential Service Organization. Environment Systems and Decisions, 40, 84-106.

Tam, L. T., Ho, H. X., Nguyen, D. P., et al. (2021). Receptivity of governmental communication and its effectiveness during COVID-19 pandemic emergency in vietnam: A qualitative study. Global Journal of Flexible Systems Management, 22(1), 45-64. https://doi.org/10.1007/s40171-021-00269-7

Ufua, D. E., Osabuohien, E., Ogbari, M. E., et al. (2021). Restrategising government palliative support systems in tackling the challenges of COVID-19 lockdown in Lagos State, Nigeria. Global Journal of Flexible Systems Management, 22(1), 19-32. https://doi.org/10.1007/s40171-021-00263-z

Ursacki-Bryant, T. J., Smart, C., \& Vertinsky, I. (2008). The Fit Between Crisis Types and Mangement Attributes as a Feterminant of Crisis Consequences. In G. P. Hodgkinson \& W. H. Strabuck (Eds.), The Oxford Handbook of Organizational Decision Making (pp. 174-193). Oxford: Oxford University Press.

Wacheux, F. (1996). Qualitative methods and management research. Economica Edition.

Weick K.E. (2003). The collapse of meaning in organizations. Mann Gulch's accident translated by Laroche H. into The Meaning of Action: Karl Weick: Sociopsychology of the Organization, Vidaillet B., Paris: Vuibert.

Weick, K. E. (1987). Organizational culture as a source of high reliability. California Management Review, 29(2), 112-127.

Weick, K. E. (1988). Enacted sensemaking in crisis situations. Journal of Management, 25(4), 305-317.

Weick, K. E. (1993). The collapse of sensemaking in organizations: The Mann Gulch disaster. Administrative Science Quarterly, $38(4), 628-652$.
Weick, K. E., \& Sutcliffe, K. M. (2007). Managing the Unexpected Resilient performance in an age of uncertainty (Vol. 2). U.S: Jossey-Bass Inc.

Yin, R. K. (2003). Case study research: Design and methods (Vol. 3). Sage.

\section{Key Questions}

(1) How can we measure the effectiveness of collective resilience in an organization?

(2) What is the link of influence between the processes of organizational resilience and the processes of collective resilience in an organization?

(3) Does the leadership influence the resilience of the organization and consequently the collective resilience in the organization?

Publisher's Note Springer Nature remains neutral with regard to jurisdictional claims in published maps and institutional affiliations.

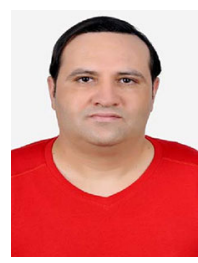

Bechir Mokline is Assistant professorat the Ibn Khaldoun University. He has a doctorate in management. He has published six articles.

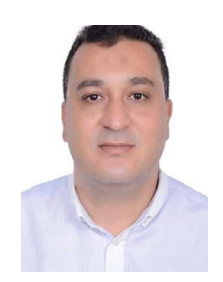

Mohamed Anis Ben Abdallah is Assistant professor at the Faculty of Economics and Management of Nabeul. He has a doctorate in management. He has published two articles. 